\title{
LA DOBLE ESCENA: USOS FILOSÓFICOS DEL TEATRO Y DISTINCIONES TEATRALES EN LA FILOSOFÍA FRANCESA CONTEMPORÁNEA
}

\author{
Nicolás Alvarado Castillo* \\ doi:10.11144/Javeriana.uph35-71.deft
}

\begin{abstract}
Resumen
El propósito de este artículo es mostrar cómo ciertos usos de términos del teatro para describir procedimientos o conceptos filosóficos revelan dos tipos diferentes de relaciones entre el discurso filosófico y las prácticas artísticas: por un lado, el uso consciente, y por lo general metafórico, que hacen algunos filósofos del vocabulario de las prácticas escénicas para describir sus propias operaciones; por el otro, la manera en que las determinaciones técnicas e históricas de esas prácticas, incluso si sin ser movilizadas por los autores con ese propósito explícito, permiten interpretar de forma distinta una construcción conceptual. Para cumplir ese objetivo se analizarán algunos momentos significativos de la filosofía francesa contemporánea -en donde abundan expresiones como escena o dramaturgia - y de la genealogía de ese interés filosófico, así como ciertas descripciones de las prácticas y de la teoría del teatro clásico francés.

Palabras clave: filosofía francesa contemporánea; filosofía y teatro; escena; Jacques Rancière; teatro clásico francés

Pontificia Universidad Javeriana, Bogotá, Colombia.

Correo electrónico: n.alvarado@javeriana.edu.co

Versiones preliminares de este texto fueron presentadas como lección inaugural del segundo semestre de 2017, en la Facultad de Filosofía de la Pontificia Universidad Javeriana, y como ponencia en el III Congreso Internacional de Literatura Comparada, celebrado en la Universidad de Costa Rica, del 3 al 6 de abril de 2018.

Para citar este artículo: Alvarado Castillo, N. (2018). La doble escena: usos filosóficos del teatro y distinciones teatrales en la filosofía francesa contemporánea. Universitas Philosophica, 35(71), pp. 379-415. ISSN 0120-5323, ISSN en línea 2346-2426. doi:10.11144/Javeriana.uph35-71.deft
\end{abstract}




\title{
THE DOUBLE SCENE: PHILOSOPHICAL USES OF THEATRE AND THEATRICAL DISTINCTIONS IN CONTEMPORARY FRENCH PHILOSOPHY
}

\begin{abstract}
The purpose of this article is to show how the use of certain terms of theatre, that are employed to describe philosophical procedures or concepts, reveals two different kinds of relations between philosophical discourse and artistic practices: On the one hand, some philosophers make a conscious and metaphorical use of the vocabulary of scenic practices to describe their own operations; on the other, the technical and historical determinations of these practices open up new interpretations of philosophical constructs, even though, at first, they were not intended to do so by the authors that exploit them. To fulfil this purpose, this article analyzes significant moments of contemporary French thought-where there are frequent expressions such as scene and dramaturgy -, in order to trace the genealogy of that philosophical interest and explore a series of descriptions of the theory and practice of classical French theatre.
\end{abstract}

Keywords: contemporary French philosophy; philosophy and theatre; scene; Jacques Rancière; classical French theatre 


\section{Introducción}

AUNQUE LA RELACIÓN ENTRE LA PRÁCTICA del teatro y la filosofía es un dato primitivo y problemático de buena parte de la cultura occidental -es decir, un vínculo que está presente desde el mundo griego clásico hasta nuestros días y que se manifiesta en casi todas las áreas culturales en las cuales se dan simultáneamente ambos fenómenos-, un momento particularmente intenso de este lazo tuvo lugar en el ámbito francés, durante la segunda mitad del siglo XX. Habiendo heredado de la generación anterior una clara disposición para combinar la tarea conceptual con la creación artística ${ }^{1}$, una parte importante de las filósofas y los filósofos franceses cuya vida intelectual comienza después de los años sesenta encontraron en el teatro algo más que un tema de investigación regional, un objeto o una materia para construir una estética o una filosofía del arte. El teatro, tal y como se actuaba en su tiempo y tal y como lo recibían de una tradición nacional de más de trescientos años, era, antes que nada, una exploración práctica de los límites de la experiencia humana y de su posible representación. Como tal, no constituía un documento cultural entre otros, listo para ser analizado; más bien, se alzaba como un modelo - posiblemente rival- de explicación de lo real, cuya potencia debía ser comprendida y reintegrada al interior del campo filosófico.

Esta tensión entre las dos formas discursivas explica por qué parece posible trazar, para esta tradición francesa que nos servirá de objeto de análisis ${ }^{2}$, una

1 Entre los que se deben contar a Albert Camus [1913-1960], Georges Bataille [1897-1962], JeanPaul Sartre [1905-1980], Simone de Beauvoir [1908-1986], Maurice Blanchot [1907-2003]. Antes de 1960, todos estos autores habían producido textos filosóficos y/o dramáticos que marcarían la relación que estamos analizando.

2 Aunque es posible incluir otros nombres y otros textos de referencia, este artículo tiene como corpus de análisis las siguientes obras de filósofos franceses contemporáneos: Jacques Derrida (1992; 2015), Michel Foucault (1994b), Gilles Deleuze (2002), Alain Badiou (2005; 2015a; 2015b), Jacques Rancière (2007; 2013; 2014; 2015), Françoise Proust (1994; 1997). El único autor no francés que está incluido, el dramaturgo y filósofo finlandés Esa Kirkkopelto (2009), realizó su investigación más relevante sobre filosofía del teatro en la Universidad de Estrasburgo, bajo la dirección de Philippe Lacoue-Labarthe, y es un invitado habitual de uno de los grupos de investigación 
relación de doble vía entre el teatro y la filosofía: la primera, aquella que se construye a través del uso analógico de términos del teatro por parte de los filósofos y cuyo fin es crear nuevos conceptos o reforzar argumentos existentes; la segunda, la descripción teatral de los conceptos filosóficos o el uso de la lógica propia de las prácticas teatrales y escénicas como revelador de la consistencia de un sistema filosófico.

Así como se ha limitado temporal y geográficamente el corpus filosófico, del vasto repertorio de términos de la tradición teatral, y que no ha hecho más que enriquecerse en las últimas décadas gracias a los estudios del performance (performance studies), solo nos centraremos en unas pocas nociones que parecen cruzarse naturalmente con conceptos filosóficos clásicos como representación, acción, repetición o ensayo. Sobre todo, la demostración estará centrada en la noción de escena, un término cuya anfibología -su posición ambigua entre una forma espacial y una unidad del discurso dramático- lo hace un candidato ideal para esta investigación sobre la doble dirección entre lo filosófico y lo teatral.

Para explorar esa relación entre el teatro y la filosofía francesa contemporánea procederemos de la siguiente manera: en un primer momento, presentaremos algunos documentos, algunas citas de textos filosóficos que, sin ser desarrollados de manera exhaustiva, tendrán la función de mostrar la evidencia inmediata de la existencia de la relación y de su particular intensidad. En seguida, indicaremos algunos hitos de la historia de la relación entre la filosofía y el teatro en Francia, con el fin de trazar una corta genealogía del problema. En una tercera parte construiremos una imagen general de la relación de analogía que une a la práctica teatral y a la teoría filosófica; es decir, con base en los resultados de la genealogía del punto anterior y en las evidencias de la primera sección, intentaremos describir los elementos estructurales de dicha comparación. En la cuarta parte estudiaremos brevemente un caso particular: el uso del término escena como categoría para describir el método filosófico de Jacques Rancière y analizaremos hasta qué

franceses más activos en este campo: el Laboratoire des Arts et Philosophies de la Scène (LAPS). Queremos indicar, además, que estos materiales serán utilizados de forma desigual: algunos serán objeto de análisis directos, mientras que otros solo serán aludidos de pasada. Por ejemplo, la noción de "método de dramatización" de Deleuze (2002) y la expresión theatrum philosophicum de Foucault (1994a), que son objeto de una investigación en curso, no serán discutidas en este artículo. 
punto este uso invita a una extensión problemática de la escena como modalidad a priori de toda experiencia humana -tal y como ocurre con los trabajos de filosofía del teatro de Esa Kirkkopelto-. Para sugerir otro acercamiento que evitaría los problemas de esta estrategia trascendental, mostraremos, en la última parte de este texto, cómo la atención a las determinaciones históricas y técnicas de los términos del teatro pueden sugerir nuevas formas de investigación filosófica.

\section{La presencia del teatro en la filosofía francesa contemporánea}

Como lo habíamos indicado, el teatro no fue solamente un objeto de reflexión teórica, un asunto más de los que ocupan a la estética como disciplina regional de la filosofía. Para esta tradición filosófica, el dispositivo dramático, tal y como se practicaba en la segunda mitad del siglo XX, presentaba dos características, que, a nuestro juicio, explican la rara intensidad con la que estos filósofos y filósofas franceses se dedicaron a la tarea de pensarlo: por un lado, su disponibilidad inmediata; por el otro, el espacio de experimentación que ofrecía, en donde parecía posible aclarar analógicamente el funcionamiento de algunos de los conceptos centrales del discurso filosófico. Por "disponibilidad inmediata” entendemos lo siguiente: que el teatro vivo, la escena contemporánea con sus dinamismos particulares, no representaba una forma de documento cultural de un pasado acabado, sino un modo de experiencia artística abierta y bajo la presión de tener que ajustarse continuamente a las nuevas fuerzas del presente. Además, si el teatro aparecía como un "espacio de experimentación" promisorio, es porque, desde finales del siglo XIX, por lo menos, y con cierto retraso con respecto a otras formas artísticas, no había dejado de sufrir lo que Peter Szondi llamó, en su Teoría del drama moderno (2011), "la crisis del drama moderno". El ideal humanístico de una forma dialógica e intersubjetiva autosuficiente se veía comprometido por la aparición de contenidos propiamente inhumanos la violencia del instinto inconsciente, las formas de dominación ideológicas, las determinaciones ciegas del mundo económico-. La forma dramática se habría entonces transformado en un lugar de experimentación incesante: primero, de producción de "tentativas de rescate" en las cuales se intentaba acomodar, en la forma antigua, los nuevos contenidos -Maeterlink, Ibsen, Strindberg-; después, de producción de "tentativas de solución" que implicaban una variación formal 
que respondiera a la emergencia de los nuevos contenidos y cuyo ejemplo paradigmático, para Szondi, como lo había sido antes para Benjamin, era la reintroducción de los elementos épicos en el teatro brechtiano. Y la filosofía francesa, desde por lo menos la segunda mitad del siglo XX, no había dejado de notar que esta tensión dialéctica entre la forma y el contenido le ofrecía ciertas lecciones difíciles de pasar por alto. Ambas características, la disponibilidad inmediata, abierta, y la proyección de un espacio reflexivo para su propia práctica, explican una notoria ansiedad en la manera como estos autores franceses asumen el problema del teatro.

$\mathrm{Al}$ no tener la posibilidad de replegarse sobre la identidad de la forma clásica consigo misma, es decir, al estar llamados a pensar la forma dramática en su variación -este es precisamente el sentido de la proliferación de "tentativas" que describe Szondi-, la manera como la filosofía había pensado el teatro pierde uno de sus apoyos más tradicionales: no puede venir, como la especulación filosófica hegeliana, a pensar post festum una realidad que parece ya haber agotado todos los momentos de su devenir; o, como lo requería la Poética de Aristóteles (1449a15), a preguntarse por la definición de la forma artística solamente cuando esta había llegado a ser completamente lo que era y cuando el hecho y la existencia de la cosa resultaban claros de antemano. Por el contrario, al teatro vivo había que pensarlo en medio de la incertidumbre de su variación. Situación que explica, además, por qué la proximidad entre los problemas formales del teatro y los procedimientos filosóficos produce esa sensación de que lo que está en juego en ese vínculo no es solamente el presente de la forma artística, sino también el porvenir de la tarea conceptual.

\subsection{LA ESCENA DE LA DIFERENCIA: DERRIDA}

REvisemos AHORA algunos lugares donde se verifica esta relación tensa, casi histérica. Cada uno tendría que ser desarrollado en otro lugar y de manera más completa. En este momento, nos interesa solamente la evidencia de su presencia y la imagen general que sugieren. Empecemos por la obra de Jacques Derrida: desde sus primeros textos, en las décadas de los sesenta y setenta, la imagen de la "escena" sirve para explicar cómo la productividad de todo texto -tanto del discurso filosófico como del literario- depende de ciertas condiciones (cuasi)trascendentales 
de visibilidad y de inscripción, condiciones espaciotemporales que permiten que se produzca la diferencia entre los signos, pero que no aparecen nunca por sí mismas, retirándose continuamente, de la misma manera como la escena teatral desaparece detrás de la acción dramática una vez la función está en curso. Los célebres conceptos derridianos de différance, archi-traza o diseminación nombran, más allá de sus matices, la sustitución y reversibilidad entre el espaciamiento (mise en espace), la puesta en texto (mise en texte) y la puesta en escena (mise en scène). Esta equivalencia entre la escritura y la puesta en escena explica por qué, por ejemplo, el sistema de huellas psíquicas que Freud describe en su interpretación de los sueños debe interpretarse como una "multiplicidad irreductible de capas sensibles" y no como una cadena de signos inscritos en una "extensión [...] pura y sin relación consigo misma” (Derrida, 1992, p. 305). Así, la distribución discontinua de la escena de la escritura que Freud "monta" le enseña al filósofo que:

la temporalidad como espaciamiento no será simplemente la discontinuidad horizontal en la cadena de los signos, sino la escritura como interrupción y restablecimiento del contacto entre las distintas profundidades de las capas psíquicas, el tejido temporal, tan heterogéneo, del propio trabajo psíquico. No se vuelve a encontrar ahí ni la continuidad de la línea ni la homogeneidad del volumen; sino la duración y la profundidad diferenciadas de una escena, su espaciamiento (Derrida, 1992, p. 309).

Ahora bien, si la escena es una buena metáfora para nombrar las condiciones que hacen pensable la producción de la diferencia y el diferimiento de las "huellas sensibles" es porque ella es capaz de ser índice de sí misma, de señalar reflexivamente su propia lógica de presentación. En "La doble sesión" (2015), al comentar el proyecto mallarmeano de una dramatización teatral del Libro, Derrida afirma esta característica crítica o trascendental de la escena: "la escena no ilustra entonces nada más que la escena, la equivalencia del teatro y de la idea, es decir, como los dos nombres lo indican, la visibilidad (excluyéndose) de lo visible en donde ella se efectúa" (p. 316).

De estas dos condiciones de la escena -ser el nombre del marco que hace posible todo fenómeno al retirarse y ser la forma de presentación o de inteligibilidad de ese mismo marco- se sigue que esta sea, en principio, la imagen de los límites de la representación. Esto también explica por qué, en "El teatro de la 
crueldad y la clausura de la representación" (1992), quizás el texto decisivo de la relación de Derrida con el teatro, la obra de Artaud aparece explícitamente como "un sistema de críticas que conmueven el conjunto de la historia de Occidente más que un tratado de la práctica teatral” (p. 322). Y, sin embargo, esa misma práctica es calificada más adelante como el único tipo de escritura o de gesto que es capaz de mostrar la repetición inherente a toda representación -la repetición originaria-, el origen del sentido que difiere de sí mismo sin punto fijo. En la descripción del teatro de la crueldad que cierra ese artículo, no es difícil ver también un reflejo de lo que el filósofo considera debe ser la tarea de la deconstrucción:

Pensar la clausura de la representación es, pues, pensar la potencia cruel de muerte y de juego que permite a la presencia nacer a sí misma, gozar de sí mediante la representación en que aquélla se sustrae en su diferancia. Pensar la clausura de la representación es pensar lo trágico: no como representación del destino sino como destino de la representación. Su necesidad gratuita y sin fondo (Derrida, 1992, p. 343).

\subsection{LA ESCENA DE LA HISTORLA Y LA RESISTENCIA MIMÉTICA:} FRANÇOISE PROUST

OTRO EJEMPLO DE LA RELACIÓN DIRECTA entre términos en principio teatrales y la práctica filosófica se encuentra en algunos apartes de la obra de Françoise Proust. Esta filósofa francesa fue una notable académica, comentarista reconocida de Benjamin, Kant y Foucault, pero, principalmente, una pensadora dedicada a reflexionar sobre el problema de la historia, la estética moderna y la idea de resistencia, entendida como una potencia vital, como categoría ontológica y como una condición indispensable de todo pensamiento libre. Su teoría sobre el tiempo histórico, que en parte hereda del idealismo alemán, de Marx y de Benjamin, compara continuamente la estructura del orden histórico-político con las formas del drama. Tanto la continuidad de la "historia de los vencedores", según la expresión de Benjamin, como la interrupción revolucionaria del tiempo histórico están situadas en un mismo plano ontológico, en una misma realidad que sin embargo se divide en dos modos de ser distintos: el ser en sí mismo como curso de las cosas, como estado y orden natural de la situación; y, como si fuera una suerte de doblez inmanente, un contra-ser, una potencia de resistencia que 
se vuelve contra él. Este plano único toma la forma de un escenario universal. Así se ve, por ejemplo, en la siguiente cita de su libro L'Histoire à contretemps (1994):

Porque si, de un lado, los dramas barrocos muestran que la existencia terrestre no es más que vanidad, drama sangriento o bufonería cómica, que la vida es un teatro de sombras o de marionetas cuyas obras pueden ser interpretadas y presentadas al público un número infinito de veces, por el otro, estos dramas hacen pasar, por el escenario de la historia, el aliento o el fantasma de otra vida, de una vida superior (p. 89) ${ }^{3}$.

Es cierto que este tópico barroco de un theatrum mundi es bastante usual en la filosofía moderna y contemporánea -y que a ese título no sabría valer como una prueba de la intensidad de la relación entre filosofía y teatro en la autora-. La singularidad de la posición de Proust consiste en que, a la concepción de la historia como espacio de representación del drama humano y como forma de orden narrativo, y con el fin de pensar la resistencia de los actores políticos revolucionarios a nivel subjetivo, ella añade criterios explícitamente "miméticos" o "fantasmales". Quien quiera resistir al presente y a su continua catástrofe debe duplicar el ser, contrariar el estado de las cosas tal y como van, imitando sus formas hasta el punto de abrir en ellas la potencia de una afirmación nueva de la vida. Para Proust en De la résistence (1997), que la resistencia tenga siempre que singularizarse desde el punto de vista del agente dominante no significa

[...] que se tenga que entrar en el juego del enemigo, situarse en su territorio y obedecer sus reglas; es precisamente lo contrario: se trata de respirarle en la nuca y de atormentar su espíritu para, imitándolo y duplicándolo, tener una oportunidad de sustraerse de su dominio (p. 162)4.

3 «Car si, d'un côté, les Trauerspiele montrent que l'existence terrestre n'est que vanité, drame sanglant ou bouffonnerie comique, que la vie est un théâtre d'ombres ou de marionnettes dont on peut jouer les pièces et qu'on peut présenter au public un nombre infini de fois, ils font passer, d'un autre côté, sur la scène de l'histoire, le souffle ou le fantôme d'une autre vie, 'd' une vie supérieure'. » En adelante, se ofrecen a pie de página los textos de las citas en su idioma original, cuando las traducciones sean propias y no se encuentren versiones en español disponibles.

4 « Entrer dans le jeu de l'ennemi, se placer sur son territoire et obéir à ses règles, c'est précisément l'inverse : il s'agit de lui coller au dos et de hanter son esprit pour, le mimant et le doublant, avoir une chance de se soustraire à son emprise. » 
La captura oblicua de la realidad por parte de quien le ofrece resistencia es entonces descrita como un juego de representación actoral o mímica, como el efecto de un mínimo de diferencia con respecto a la realidad que libera las fuerzas que componen un efecto de subjetivación.

\subsection{LA ESCENA DE LA REPRESENTACIÓN DE LA IDEA: ALAIN BADIOU}

Un último ejemplo, el de Alain Badiou, nos muestra no solo la intensidad de la relación -él describe, en "Teatro y filosofía”, el vínculo entre la filosofía y la práctica escénica como "tenso, paradójico, probablemente tan decisivo como oscuro" (2005, p. 118) - sino la acumulación masiva de su evidencia: además de una extensa obra dramática, Badiou ha escrito más de una decena de artículos sobre teatro y filosofía en revistas especializadas como Les Cabiers de la ComédieFrançaise y L'Art du théatre y es el autor de al menos dos libros importantes sobre el tema: Rapsodia para el teatro (1990/2015) y Éloge du théatre (2013). Ahora bien, a pesar de la multiplicidad de textos y de los cambios de orientación que ha experimentado su filosofía, la definición que da Badiou del teatro permanece relativamente invariable: "teatro: la corporeización de la Idea" (1990/2015, p. 126), "el teatro, cuando tiene lugar, es una representación de la Idea" (2013, p. 63). ¿Cuáles son entonces las condiciones que hacen posible que en la representación teatral se le dé forma o cuerpo a lo universal del pensamiento, a la Idea? Badiou (2005) propone cuatro rasgos generales para resumir ese sistema de condiciones:

(I) "El teatro es un acabamiento". La relación entre la representación en escena y el texto es, para Badiou, equivalente a la relación entre lo actual y lo virtual, o entre la finalización material y la incompletud textual. El teatro sería entonces el acontecimiento, la venida en acto de la virtualidad de una Idea dramática. Es sobre el escenario, y en ninguna otra parte, que acontece la verdad del teatro. Pero hay que notar que este acontecimiento está marcado por una materialidad estricta -el cuerpo de los actores, la presencia siempre cambiante de los espectadores, las condiciones técnicas de producción- que lo indexa a una forma de azar constitutivo. Y es por este azar ineluctable que el acontecimiento-teatro no es simplemente la puesta en forma de una composición abstracta, sino la urgencia de hacer que una invención 
formal nueva -el índice material y singular de la escena- toque lo real de un acto como su Idea o infinito artísticos.

(II) El teatro es la experimentación de un tiempo singular, en el que se encuentran "la eternidad y el instante". El momento de la representación no es solo una composición de gestos o de palabras, es simultáneamente una composición o un montaje de tiempos. Se conjugan, en la duración de la representación, la "eternidad" de la figura -Hamlet, por ejemplo- y el "instante" de la actuación. En el escenario, y cada vez de manera distinta, casi como un experimento, hay una síntesis de tiempos heterogéneos. Una vez más, los cuerpos, la voz, la iluminación, etc., son materiales contingentes y azarosos con los cuales se propone una "culminación" de la Idea teatral.

(III) El teatro es, por su destinación esencial, público. El acontecimiento y la experimentación de la Idea en el teatro solo pueden ocurrir bajo el presupuesto del "encuentro" teatral. La presuposición de un público como condición necesaria para la representación es la dimensión "cuasipolítica" del teatro. Y, además, ese público debería estar compuesto de la forma más azarosa posible -la descripción de Badiou es en este caso normativa-. Esta composición le impedría representar únicamente a una clase social determinada, o a una comunidad definida, y lo convertiría en la presentación de una humanidad genérica.

(IV) El teatro aclara una situación de la existencia histórica. El dispositivo teatral funciona como un amplificador del tiempo histórico en el que se inscribe. Intensifica y hace más legibles ciertos rasgos del presente. Buena parte de este efecto de clarificación del presente se lo debe el teatro a su relación con el Estado, a la manera como, para Badiou, la representación teatral exhibe y pone a distancia las formas políticas

5 Por ser esta forma de presentación sensible que depende, en cuanto a su verdad, de la capacidad de articularse a través de los efectos de un acto singular, Badiou sostiene, en El siglo (2004), que el arte del siglo XX, siglo que estuvo marcado por la "pasión por lo real", fue eminentemente teatral: "Instalaciones, acontecimientos, happenings, improvisaciones: todo orienta la búsqueda hacia una suerte de teatralidad generalizada, porque el teatro siempre se hizo cargo de que era un arte precario, artesanal, ligado a innumerables contingencias públicas. Que lo infinito, con una forma parcial pero rigurosamente decidida pueda ser la resultante de un azar escénico: tal es el ideal del siglo" (p. 197). 
-o el "estado de las cosas"- que le son contemporáneas. "Incapaz de mostrar la revolución, atrapado en los intersticios del Estado, ¿no es el teatro -se pregunta Badiou en su Rapsodia (2015) - el único arte que establece una visibilidad del Estado? ¿El único arte que lo muestra?” (p. 72). Y más adelante añade:

Pero hay una torsión, característica de la escena: forma del Estado, el teatro no puede sino mostrar "otro estado" de las cosas respecto de aquel del cual es una forma. El teatro distancia el Estado que muestra, porque esta mostración es informada, puesta en forma, a partir del Estado mismo. (p. 73)

¿Qué tienen que ver estos rasgos del teatro con la manera como opera la filosofía y con su batería de conceptos? Como es de esperarse, para Badiou la filosofía está intrínsecamente ligada a la clarificación de lo que sea una Idea, de su origen en un acontecimiento y de cómo esta se presenta o se incorpora en una serie de materiales particulares y contingentes. De hecho, en su Segundo manifiesto por la filosofia (2010), Badiou caracteriza su empresa filosófica como un materialismo y un comunismo de la Idea.

La filosofía también está, desde su origen griego, llamada a pensar la relación entre la particularidad del presente -una verdad siempre surge en un punto de un mundo determinado- y lo que, por la universalidad de su destinación y la singularidad de su origen, tiene que ser pensado en un modo temporal radicalmente diferente a la finitud de la experiencia individual -la eternidad-. Como la política, y como la dimensión política del teatro, la filosofía se ofrece, en principio, a todos por igual; y tal como la amplificación del dispositivo teatral, la filosofía tiene como tarea existencial orientar al individuo en su proceso de subjetivación, lo que quiere decir poder evaluar su situación y el mundo histórico en el que existe, más allá de su pura contingencia o particularidad.

Cerremos por ahora este examen, que tenía como objetivo hacer manifiesta la existencia de un vínculo constante de la filosofía francesa con el teatro y su singular intensidad. Queda abierta, todavía, una pregunta simple: ¿por qué este interés?, ¿de dónde viene? 
2. Breve genealogía de la relación entre la filosofía francesa y el teatro

El peligro de todas las genealogías, desde Nietzsche, es que siempre acaban en los griegos. A algunos los reconforta que todos los caminos lleguen a Atenas -con escala en Roma-. A nosotros, como a Nietzsche también si se lee atentamente el Nacimiento de la tragedia, nos inquieta ese origen que oscurece todo lo que lo antecede y sobredetermina todo lo que lo sucede. Así que la genealogía del interés filosófico y francés por el teatro que se propone acá será deliberadamente corta, su límite absoluto será el surgimiento de un teatro nacional y cortesano en la Francia del siglo XVII ${ }^{6}$.

\subsection{EL TEATRO VIVO, EL TEATRO POPULAR Y LA ESCUELA REPUBLICANA}

EL PRIMER ELEMENTO que queremos destacar es más bien evidente y ya lo habíamos tocado de alguna manera en la primera sección. Si los filósofos y las filósofas franceses se interesaron (y se interesan) tanto por el teatro, es porque tuvieron un contacto real, vivo, con su práctica. De múltiples maneras: algunos fueron traductores de piezas extranjeras; otros fueron dramaturgos y firmaron numerosas obras de teatro o de ópera; otros más, directores; algunos, incluso, actores en compañías de tamaño considerable. Y a esa participación directa en la cosa teatral, añadamos que tuvieron frecuentes colaboraciones con los creadores más destacados del teatro contemporáneo: Jean Genet, Samuel Beckett, Pierre Guyotat, Antoine Vitez, Patrice Chéreau, Hélène Cixous, Michel Deutsch o Michèle Foucher, por citar solo a algunos.

Otro elemento que podemos mencionar, y que sin duda influyó en ese interés por las tablas y por la expresión dramática, tiene que ver con el peso simbólico de la escritura teatral clásica -lo que incluye la melopea de su representación en escena- y de la tradición del teatro popular en el sistema educativo francés y en

6 Con todo, el tema de la imitación de los antiguos sigue siendo central en la filosofía y en la historia de las letras francesas. Sobre la relación de esta imitación del mundo griego clásico con el teatro y su importancia para la filosofía de las artes escénicas, véase el libro Scène de Philippe Lacoue-Labarthe y Jean-Luc Nancy (2013). 
el campo cultural republicano ${ }^{7}$. El resultado de esos dispositivos educativos y teatrales es una extraña ambivalencia afectiva hacia el teatro clásico: por un lado, aparece como la fuente siniestra de toda la coerción disciplinar de la escuela y como el modelo que debe ser superado por las experiencias nuevas del teatro democrático; por el otro, se lo incorpora como estructura paradigmática de la claridad de estilo, de buen orden de composición y de elegancia en la dicción. Paul Claudel, gran poeta y autor de teatro de finales del siglo XIX y principios del XX, es un ejemplo clarísimo de este sentimiento ambivalente. Sus ataques violentos a la tradición del teatro burgués de la segunda mitad del siglo XIX y a los ritmos métricos heredados del siglo XVII lo llevaban a decir, por ejemplo, que aquello que más detestaba de toda la literatura francesa era ese "ronroneo gris y elegante" de Berenice de Racine. Y, sin embargo, al final de su vida, en uno de sus últimos textos publicados - Conversations sur Jean Racine (1956)- Claudel afirmaba sobre el verso de la poesía dramática clásica:

ARCAS: Medirse, dice uno de forma tan magnífica en francés. Los actores se miden los unos a los otros. Con la vara y el radar. Toman conciencia por la oposición de su propia medida personal.

Paul Claudel: De ahí el uso del alejandrino.

ARCAS: iQue antes había usted criticado tan severamente en su empleo dramático! [...] Y, sin embargo, lo admite usted en la obra de Racine.

Paul Claudel: No solamente lo admito, sino que lo aplaudo, iy con las dos manos! Era el motor adecuado para la necesidad que tenía. Hablábamos hace un momento de medida. ¿Qué otra cosa es un par de alejandrinos si no el pensamiento que, a cada paso, se mide y se compara consigo mismo, que retoma el equilibrio, como un pie sobre el otro, en un progreso cuyo tempo es uno de los elementos de belleza, y que se procura a sí mismo y por sí mismo una conciencia enriquecida? (p. 26)

7 Uno de los estudios históricos más completos sobre el teatro popular francés es el texto de Jessica Wardhaugh Popular Theater and Political Utopia in France 1870-1914. Active Citizens (2017).

8 «Arcas: Se mesurer, dit-on magnifiquement en français. Les acteurs se mesurent l'un avec l'autre. Avec la toise et le radar. Ils prennent conscience par l'opposition de leur propre mesure personnelle. Paul Claudel: De là cet emploi de l'alexandrin. 
La consecuencia más importante de la cita de Claudel es que el modelo o la imagen del pensamiento para un intelectual francés, la representación natural de qué es pensar, del ritmo y la cadencia que hace avanzar al pensamiento, está fuertemente condicionada por ese largo y bellísimo verso de doce sílabas métricas en el que se escribieron los géneros mayores del teatro desde el siglo XVII hasta el XIX. Los franceses cultos, hasta mediados del siglo XX, cada vez que pensaban en qué significa pensar, pensaban en versos teatrales.

\subsection{DE LA ESCENA PRIMITIVA A LA OTRA ESCENA: EL PSICOANÁLISIS $Y$ EL TEATRO}

UN TERCER ELEMENTO DE ESTA GENEALOGía es la mediación del psicoanálisis. Lo que tiene de teatral el recurso a Edipo es una cosa absolutamente conocida. Pero más allá de esa referencia fundacional y estructural, la escena funcionó como una especie de significante flotante en el discurso psicoanalítico. Tomemos por ejemplo la Urszene de Freud, la escena originaria: ¿qué nombraba?, ¿y para qué servía? En principio, la escena originaria o primitiva servía para designar la circunstancia, real o imaginaria, en la cual el niño es testigo de la relación sexual de sus padres, que además interpreta como un acto violento. Ese acontecimiento es la raíz de una sensación de angustia y una pieza clave en la configuración de las formas fantasmáticas del deseo en el individuo9. Pero quizás lo realmente interesante de ese uso de la noción de escena en Freud sea la heterogeneidad de los elementos que pone en juego. La noción de escena le sirve para mantener juntas diferentes determinaciones epistemológicas, filosóficas y estéticas: la escena

Arcas : Que vous avez si vertement critiqué autrefois pour l'usage dramatique [...]. Et cependant vous l'admettez chez Racine!

Paul Claudel: Je ne l'admets pas seulement, j'y applaudis! Des deux mains! C'était l'engin adéquat dont il avait besoin. Nous parlions de mesure tout à l'heure. Qu'est autre chose le couple alexandrin que la pensée qui à chaque pas se mesure et se compare à elle-même? Qui reprend, dans un avancement dont le tempo est un élément de beauté, équilibre comme d'un pied sur l'autre? Et se procure d'ellemême à elle-même une conscience enrichie ?»

9 El primer uso del término está en el célebre caso del hombre de los lobos, "De la historia de una neurosis infantil" (Freud, 1918/1992), aunque la fantasía del acto sexual de los padres aparece en obras más tempranas como origen de las formas sintomáticas neuróticas. 
presenta, simultáneamente, un evento factual, una fantasía primaria o filogenética y una construcción analítica.

El psicoanálisis lacaniano, cuya influencia en la filosofía francesa contemporánea es capital, también está fuertemente marcado por esta batería de metáforas teatrales. Compartirá con Freud la noción de que el nivel escópico de la pulsión está detrás de todo el registro de lo imaginario, de que todo deseo que se muestra, por más articulado que esté por el campo simbólico del lenguaje y de la ley, siempre aparece como fantasma -como el fantasma del padre de Hamlet, por ejemplo, que recibe un largo comentario en el Seminario 6, El deseo y su interpretación (2014)-. "El fantasma es el teatro particular del sujeto -dirá Antonio Quinet describiendo la teoría lacaniana en su artículo "L'inconscient structuré comme un théâtre" (2010)- donde repite y ensaya sus aventuras de gozo con sus objetos-compañeros. Y hace su puesta en escena para Otro, para el público del inconsciente"10 (p. 192).

Además, tanto Freud como Lacan insisten sobre el vínculo que existe, para el psicoanálisis, entre la puesta en escena que realiza la paciente histérica y la mirada del maestro (el analista). Esta relación entre el analista-espectador y la pacienteactriz, cuyo momento fundacional debe buscarse en la práctica de Charcot en el hospital de la Salpêtrière ${ }^{11}$, da forma a la cura analítica. La noción misma de transferencia está ligada a esa "otra escena" (der andere Schauplatz) donde lo que hay de más en la presentación del síntoma se vuelve un posible saber.

\subsection{EL TEATRO, LA CIVILIZACIÓN Y LA NATURALEZA}

Un ÚLTIMO ESLABÓN en esta búsqueda del origen del sentimiento ambivalente hacia el teatro y del deseo de compararlo con el concepto filosófico tiene que ver con el lugar que ocupó el teatro en el debate entre naturaleza, arte y sociedad en

10 « Le fantasme est le théâtre particulier du sujet où il répète ses aventures de jouissances avec ses objetspartenaires. Il fait sa mise en scène pour un Autre, le public de l'Inconscient. 》

11 Sobre la dimensión "especular" y "espectacular" de la histeria y sobre el registro en imágenes de las experiencias clínicas de Charcot, véase el texto de Georges Didi-Huberman La invensión de la histeria. Charcot y la iconografía fotográfica de la Salpêtrière (2007), especialmente el capítulo 7, "Repeticiones, escenificaciones" (pp. 235-339). 
la filosofía ilustrada francesa. Tomemos a Diderot y a Rousseau como los dos adversarios en disputa, aunque si se examina con propiedad, en cada uno de ellos está lejos de resolverse la tensión entre la virtud política, la imitación artística y la disposición natural. En principio, Diderot aparecería como uno más de los filósofos parisinos -como D’Alambert-, amante de los efectos civilizatorios del teatro, convencido de que la imitación artística es un perfeccionamiento lento y laborioso de los dones de la naturaleza ${ }^{12}$. De ahí la importancia, para los actores -y también para los ciudadanos-, de conocer el arte de imitar y los principios que lo gobiernan. Es más, si se requiere algo para que la acción, en la escena o en la sociedad, sea armoniosa, justa y bella, es que la naturaleza no haya entorpecido al alma con una sensibilidad exagerada. Se trata de la famosa paradoja del actor, desarrollada en Le paradoxe sur le comedien (1981):

[...] los grandes poetas, los grandes actores, y quizás todos los grandes imitadores de la naturaleza, cualesquiera que sean, dotados de una bella imaginación, de un gran juicio, de un fino tacto y de un gusto muy seguro, son los seres menos sensibles (Diderot, p. 131).

Los atributos que hacen grande a un actor y justo a un ciudadano siguen siendo naturales, pero no se trata ya de una sensibilidad que sea la fuente inmediata de la espontaneidad de la representación o de la certeza moral, sino de un principio plástico de perfectibilidad, una disposición a tolerar lo nuevo, lo imprevisible y lo provisorio ${ }^{13}$. De un gran actor, Diderot espera "mucha perspicacia y ninguna

12 De ahí que el teatro aparezca, en "Entretiens sur le Fils naturel" (1981), como la fiesta cívica por excelencia y el ideal de la celebración republicana. « Tous lespeuples ont leurs sabbats et nous aurons aussi les nôtres. Dans ces jours solennels, on représentera une belle tragédie, qui apprenne aux hommes à redouter des passions ; une bonne comédie qui les instruise de leurs devoirs et qui leur en inspire le goût » [Todos los pueblos tienen sus sabbats y nosotros tendremos también los nuestros. En esos días solemnes representaremos una bella tragedia que enseñe a los hombres a temer a las pasiones; una buena comedia que los instruya en sus deberes y que les inspire el gusto por ellos] (Diderot, p. 52).

13 La sensibilidad humana es condición de la perfección posible del espíritu, motivo de la virtud moral y de la acción poética. Por ejemplo, en el Salón de 1767, al definir el ritmo de una composición poética, dice Diderot (1876) lo siguiente: «Qu'est-ce donc que le rhythme? me demandez-vous. C'est un choix particulier d'expressions; c'est une certaine distribution de syllabes longues ou brèves [...] analogues aux idées qu'on a, et dont on est fortement occupé; aux sensations qu'on ressent et qu'on veut exciter; aux phénomènes dont on cherche à rendre les accidents; aux passions qu'on éprouve, et au cri animal qu'elles arracheraient; à la nature, au caractère, au mouvement des actions qu'on se propose de rendre; et cet art-là n'est pas plus de convention que les effets de l'arc-en-ciel; il ne se prend point; il ne se 
sensibilidad, el arte de imitarlo todo, o lo que viene a ser lo mismo, una aptitud igual para todo tipo de caracteres y de papeles" (1981, p. 127). Esta defensa de la creación social del individuo permite a Diderot proponer una reforma del arte dramático y un nuevo género teatral: el "género serio". Más que por la mezcla formal entre lo trágico y lo cómico, el nuevo género se define por la sustitución de la representación de los caracteres psicológicos - unidad natural del sentimiento- por la imitación de las condiciones ambientales -las relaciones, socialmente construidas, que definen las acciones de los hombres-.

Sin embargo, esta defensa de Diderot de la sociabilidad teatral no se presenta sin contradicciones. Para describir esa misma sensibilidad que desorganiza al cuerpo social y deshace su vínculo, Diderot no retrocede en utilizar las mismas referencias al teatro: "los hombres ardientes, violentos, sensibles están en escena; ellos dan el espectáculo” (1981, p. 131). Con ese mismo gesto, Diderot renueva el vínculo con la tradición barroca de la "comedia del mundo" y la vanidad de la representación. Y, en sus ensayos de crítica pictórica de los Salones, la noción de teatro está frecuentemente asociada a la convención artificial y al agrupamiento impostado de figuras. Para componer cuadros bellos, había que negar un cierto tipo de teatralidad de la representación y encontrar un estilo natural o ingenuo.

Por el lado de Rousseau, la posición inicial es la contraria de la de Diderot. Aquellos que van al teatro, a los espectáculos, queriendo ejercer su sociabilidad terminan por descubrir que el drama que se desarrolla en escenario solo puede alejarlos de sus conciudadanos y de sí mismos. El teatro es el lugar paradigmático en el cual los hombres creen tener el derecho de suspender sus vínculos con la comunidad. La continua variación de las formas de representación y de sus contenidos, el engaño asumido momentáneamente como verdad y como virtud, no hacen más que distanciar al sujeto de la unidad de su propia conciencia moral. De esta manera, hay que oponerse de la forma más resuelta posible a la instauración, política y

communiquepoint; ilpeut seulement seperfectionner. 》 [¿Qué es el ritmo?, me pregunta usted. Es una escogencia particular de expresiones; una cierta distribución de sílabas largas o breves [...] que son análogas a las ideas que tenemos, y de las cuales nos ocupamos con suma atención; a las sensaciones que experimentamos y que queremos excitar; a los fenómenos, cuyos accidentes buscamos restituir; a las pasiones que sufrimos y al grito animal que nos arrebatan; a la naturaleza, al carácter, al movimiento de las acciones que nos proponemos traducir; y ese arte tiene tanto de convencional como los efectos del arcoíris; ese arte no se atrapa ni se comunica, solamente se puede perfeccionar] (p. 268). 
moralmente nefasta, del teatro en la ciudad. Y, sin embargo, para Rousseau, hubo por lo menos un momento histórico en el cual el teatro fue más que solo una técnica artística nociva, en el que fue la presencia natural de la comunidad frente a sí misma, es decir, religión: el momento de la tragedia griega. Rousseau anticipa con esto, de manera rigurosa, los análisis hegelianos, románticos y nietzscheanos de la religión del arte. Si el teatro griego podía mostrar las representaciones más odiosas, si sus espectadores eran capaces de soportarlas, era porque en el fondo nunca hubo ni teatro ni espectador griego. Solo hubo la celebración, la asamblea, de un pueblo que se reunía para comunicarse sus "sus penas y sus gozos". La oposición entre la naturaleza y la cultura se resolvía entonces no por la clausura del teatro, sino por la retracción del teatro mismo, del espectáculo, a un principio originario anterior a su devenir histórico: el final del teatro, su acabamiento y su disolución, se volvía idéntico a la instauración de un archi-teatro, de un teatro original donde la actividad imitativa quedaba purificada de cualquier contenido y al abrigo de toda contingencia ${ }^{14}$. Tal actividad, mímesis de nada, es decir, mímesis pura, lleva el nombre de "fiesta cívica". Hacia el final de la "Lettre à D’Alambert" dice Rousseau (1758/1995):

¿Cómo? ¿No se necesita entonces espectáculo alguno en la República? ¡Al contrario, se necesitan muchos! Es en las Repúblicas donde estos han nacido; es en su seno que los vemos brillar con un verdadero aire de fiesta. [...] Pero no adoptemos más esos espectáculos exclusivos que encierran tristemente a un pequeño número de personas en un antro oscuro, que las mantiene temerosas e inmóviles en el silencio y la inacción; que no ofrece a los ojos más que encierros, puntas de lanzas, soldados, imágenes penosas de la dominación y de la desigualdad. ¡No, pueblos felices, estas no son sus fiestas! Es al aire libre, bajo el cielo, que deben reunirse y entregarse al suave sentimiento de su felicidad. [...] ¿Cuáles serán los objetos de estos espectáculos? Nada, si se quiere. [...] Planten, en medio de una plaza una lanza coronada de flores, reúnan allí al pueblo, y tendrán ya una fiesta. Mejor aún: muestren a los espectadores en

14 Sobre el problema de la mímesis y la representación teatral en Rousseau, véase el ensayo La poétique de l'histoire de Philippe Lacoue-Labarthe (2002). 
el espectáculo; háganlos, a ellos mismos, actores; hagan que cada uno se vea y se ame en los otros, con el fin de que estén mejor unidos (p. 114).

Casi un siglo después de su codificación canónica clásica -el Art poétique de Boileau fue publicado por primera vez en 1674-, el teatro francés era, a los ojos de los filósofos, simultáneamente la única celebración pública digna de una comunidad libre y el epítome de todos los vicios de la civilización; la fuente de una vida social enriquecida y la forma endurecida de costumbres obsoletas.

\section{La estructura de la analogía: funciones filosóficas de la escena}

Podemos aHORA Resumir esquemáticamente los elementos que, en los dos apartados anteriores, resultan significativos a la hora de comparar los procedimientos del arte dramático -especialmente la noción de escena- y las operaciones conceptuales de la filosofía. Estos elementos suponen una cierta coherencia entre ellos y forman una unidad compleja; la separación es, en este caso, más una necesidad metodológica y de exposición. La noción teatral de escena, cuando es comparada con los procedimientos o los conceptos filosóficos, cumpliría en consecuencia con las siguientes cuatro funciones:

(1) Función espacial: Quizás la característica más evidente, pero no la menos problemática, del dispositivo escénico es el corte en el espacio que este implica. Una escena circunscribe o encuadra una serie de fenómenos. Así tengamos la costumbre de llamar al puro espacio arquitectónico, vacío y antes de la representación, una escena, esta solo existe en función de la posibilidad de la representación. Ningún lugar en el que no sea al menos posible la aparición de un fenómeno puede ser una escena. La escena, como lugar o espacio que, sin ser la representación, la condiciona y la hace posible, aparece entonces como una determinación cuasitrascendental de toda presentación. Y así como la escena es un espacio que no se confunde con las acciones representadas pero que es inseparable de ellas, el pensamiento conceptual tendría su propio espacio de encuadre y su propio territorio de efectuación. Ese espacio determina al mismo tiempo los dinamismos virtuales y las variaciones de intensidad que preceden al concepto y que sin embargo permanece inmanente durante la actualización de la representación. El "espaciamiento" en Derrida, el concepto de Deleuze-Guattari de un plano de inmanencia filosófico y ciertas descripciones de Foucault sobre los 
espectáculos de Raymond Roussel como "contornos de visibilidad" comparten con la escena esta idea de una composición múltiple de espacios.

(2) Función temporal: No solo el espacio de la escena está indisolublemente ligado a sus contenidos, a las acciones dramáticas. También el tiempo de la escena es indisociable del tiempo de las representaciones. Es una antigua herencia, que tiene que ver con la distinción entre los posibles modos de enunciación de la poesía -el famoso asunto de la lexis en la poética griega-: la distinción entre el modo dramático y el narrativo. En el teatro, los contenidos del relato son enunciados a través de la imitación directa de los actores y no por medio de la narración del autor. Esta forma dialógica y mimética del drama hace casi imposible, por lo menos en un primer nivel, que el tiempo del relato no coincida con el tiempo de la historia. La forma dramática, entonces, fuerza a sus espectadores a pensar en una duración casi simultánea de la presentación en general y de los eventos interiores representados. Sin embargo, incluso si este "instante" dramático parece dominar sin resto la temporalidad de la escena, otras experiencias del tiempo están a la obra: la estructura narrativa anterior e indefinida del texto dramático; la atención desigual de los espectadores; la tensiones, anticipaciones o retroacciones de los actores. Esta es la fragilidad, la belleza delicada del teatro. Toda presentación es, propiamente hablando, irrepetible. No hay dos funciones iguales de una misma obra. Y sin embargo es esa misma obra la que, noche tras noche, se repite al frente del público; esa misma que día tras día, se ensaya -en francés se dice también se repite- a puerta cerrada. Las repeticiones ponen en juego las determinaciones virtuales del texto y de la obra, y desencadenan las experiencias posibles de los actores y espectadores. La repetición, la creación de una representación singular, no es simplemente el descenso o la encarnación de la Idea eterna. Por el contrario, y esto también valdría, según ciertos autores, para las construcciones filosóficas, la repetición tiene como objeto someter la eternidad de la Idea a la prueba de la variación. No para verificar que, a pesar de las diferencias en cada presentación, ella permanece igual a sí misma, sino para examinar qué nuevas potencias no han sido aún desarrolladas y para afirmar que la Idea, más que una realidad única e indivisible, es un conjunto relativamente estable de problemas.

(3) Función escópica: En toda escena algo pasa, y eso que pasa se ofrece a la mirada de alguien. ¿Cuál es la estructura de esa mirada teatral? No se trata de un simple punto geométrico que organiza una estructura de dirección -frente 
a quién se actúa- y que limita el campo de representación -hasta qué lugar debe permanecer el actor en su rol, cómo se sale de escena, etc.-. Esa mirada tiene dos características esenciales: es una mirada anónima, no porque no lleve conmigo, al teatro, mis prejuicios y mis particularidades como espectador, sino porque la mirada se integra forzosamente a una representación que se ofrece a todos por igual. El teatro compartiría, según Badiou por ejemplo, ese rasgo de la destinación universal y sin restricciones de la verdad con el discurso filosófico. La segunda característica de esa mirada es que está cargada afectivamente. Así sea bajo la forma de la proyección imaginaria del fantasma o bajo la clásica contaminación de las pasiones y la purgación catártica, la mirada teatral implica la articulación de una imagen -la representación en escena- y una carga afectiva determinada. Aclarar el saber que produce ese vínculo -efectuar su saber y escribir su matema, diría Lacan-, y con ello abrir el espacio clínico para que el deseo se inscriba de manera coherente con la vida del sujeto, ese es todo el asunto de la práctica analítica. Y en ese difícil paso que hace que algo de lo real se asuma en la transformación del fantasma en saber -se trata del nudo de la cuestión de la ideología y de la ciencia-, se ha jugado buena parte del destino de la filosofía política francesa contemporánea, aquella que comúnmente se conoce como post-marxista. Aclarar el presente, aclarar su orden histórico-político para transformarlo o para resistirlo, solo es posible en la medida en que las formas de representación de lo que somos estén efectivamente vinculadas con el deseo y con la voluntad.

(4) Función performativa: Hay en toda puesta en escena la presentación de un vínculo singular entre la palabra, el pensamiento y la acción. En toda escena, una forma de expresión determinada, un campo de sentido impersonal y una disposición particular de los cuerpos se combinan. No siempre esa combinación es armónica, y cualquiera de los tres términos -la palabra proferida, el contenido enunciado y el gesto ejecutado- puede presentarse en exceso sobre los otros dos. Esa lógica de composición, en la que un sujeto se divide entre la potencia virtual del personaje, la realidad actual del actor y la repetición incorporal del lenguaje, aparecerá en varios de los conceptos que la filosofía francesa contemporánea ha creado para explicar la emergencia de un sujeto artístico o político y para pensar su capacidad de articular nuevas formas sensibles de lo común. 


\section{El uso metodológico de la escena en Rancière: una forma suplementaria de la analogía}

LOS INTENTOS DE COMPARAR CONCEPTOS FILOSÓFICOS con la forma o la experiencia de la escena parecen usar, redistribuir o combinar las funciones descritas anteriormente. No se trata de afirmar que esos cuatro elementos agoten todos los usos imaginables de la escena en la filosofía, sino de verificar hasta qué punto las nuevas determinaciones que pudieran encontrarse responden o no a un agenciamiento particular, a una interpretación determinada, de este sistema de funciones. $\mathrm{Si}$, por ejemplo, se piensa en la escena como un posible soporte de improvisación ${ }^{15}$, habría que examinar cómo el movimiento discontinuo, la pluralidad de centros de percepción-acción, la multiplicidad de puntos de contacto o de focalización, son o no descriptibles en los términos más abstractos de los marcos de referencia espaciales, de composición heterogénea de bloques de tiempo, de variaciones afectivas o de efectos performativos. De no ser pensable el ajuste, conviene examinar si el fenómeno en cuestión no estaría, precisamente, transgrediendo el límite de la escena y renunciando a tomarla como operador de comparación para el campo filosófico ${ }^{16}$.

15 A propósito de la improvisación y de la relación entre las artes vivas - particularmente la danza- y la filosofía, véase el sugerente libro de Marie Bardet Penser et mouvoir. Une rencontre entre danse et philosophie (2011).

16 Nos parece, en efecto, que es lo que ocurre en el trabajo filosófico sobre la danza de Marie Bardet (2011), al que nos referimos en la nota anterior: «La danse, mouvement qui crée l’espace vide. Je suis là parce que je ne suis plus là où j'étais. Je bouge et je crée des vides, je me meus et je crée en creux. Et plus il y a de l'espace, de vide, dans le corps, dans chacune des articulations, plus l'échange des espaces, du corps et du contexte, est riche et à double sens, plus la composition est claire, le corps marque l'espace comme autant de traces qu'il y laisse, séparées par des vides clairs, qui donne composition et donc sens, goût et portée à la "chorégraphie" du moment. Travail agraire des sillons tracés sur scène, ou ailleurs. Évidage-évidence de l'espace plein du théâtre, le sens pousse tout seul comme la mauvaise herbe dès que le sol a été retournépar la lame d'acier. 》 [La dansa, movimiento que crea el espacio vacío. Estoy ahí porque ya no me encuentro ahí donde estaba. Me muevo y creo vacios, me muevo y creo a contrarrelieve, implícitamente. Y entre más espacio hay, entre más vacío hay en el cuerpo y en cada una de las articulaciones, el intercambio de espacios, de cuerpos y del contexto se vuelve más rico y ocurre en doble sentido; entre más clara es la composición, el cuerpo marca el espacio como las tantas huellas que ha dejado, huealles separadas por vacíos claros y que dan la composición y, por lo tanto, el sentido, el gusto y el alcance de la "coreografia" del momento. Trabajo agrario en los surcos trazados en la escena, o en otro lugar. Vaciamiento-evidenciamiento del espacio pleno del teatro, el 
En el resto de esta sección, examinaremos un uso de la noción de escena que, si bien parece conforme a los elementos descritos anteriormente, presenta una particularidad interesante: su extensión varía con respecto a los ejemplos anteriores. En este caso, la analogía con la escena ya no funciona para describir una similitud parcial con un concepto filosófico o una práctica especulativa específica, sino para describir la totalidad de un método de trabajo -la noción de escena como parte integral de todo el "método de la igualdad" de Jacques Rancière-. La radicalidad de este gesto, aunque seductora, no viene sin ciertos riesgos o inconvenientes teóricos que señalaremos más adelante.

El término "escena" aparece de manera insistente en la filosofía de Jacques Rancière. Desde sus contribuciones para la revista Les Révoltes Logiques -como lo recuerda Peter Hallward en "Jacques Rancière et la théâtrocratie" (2006)-, la política de emancipación es representada como la instauración de una escena de palabra y de razones. En El desacuerdo (2010), la "toma de la palabra” de quienes estaban excluidos de un orden social -el dispositivo de subjetivación política fundamental- se describe como una "capacidad de producir esos escenarios [scène] polémicos, esos escenarios [scène] paradójicos que hacen ver la contradicción de dos lógicas, al postular existencias que son al mismo tiempo inexistencias o inexistencias que son a la vez existencias" (p. 59). La escena también será objeto o herramienta de análisis en textos posteriores, cuando la atención de Rancière se concentre de manera particular en el vínculo entre la distribución de lo sensible que ocurre en el arte y el reparto del mundo común que presupone la política. Entre estos se encuentran: "El teatro de las imágenes" (2007), "Los gimnastas de lo imposible. París, 1879", “El teatro inmóvil. París, 1894-1895” y "La escalera del templo. Moscú-Dresde, 1912” en Aisthesis (2013), o el largo ensayo que cierra El hilo perdido. Ensayos sobre la ficción moderna (2015) y que lleva el nombre de "El teatro del pensamiento". En todos estos textos, la escena es tomada como construcción, conceptual o sensible, que permite el encuentro de múltiples heterogéneos y desafía el orden, siempre jerárquico y consensual, de lo que comúnmente significa pensar, hacer o decir.

sentido crece solo, como la mala hierba cuando el suelo ha sido revuelto por la hoja de acero] (p. 128 [el énfasis es nuestro]). 
Sin embargo, la escena le sirve a Rancière para pensar otra cosa aún: para describir sus propios procedimientos filosóficos. El uso de la analogía teatral adquiere un valor metodológico. En una conversación con Laurent Jeanpierre y Dork Zabunyan publicada bajo el título El método de la igualdad (2014), Rancière afirma:

La escena es una entidad teórica propia de aquello que denomino método de la igualdad porque destruye al mismo tiempo las jerarquías entre los niveles de realidad y de discurso y los métodos habituales para juzgar el carácter significativo de los fenómenos (p. 99).

En este sentido, la escena como práctica del método de igualdad tendría como objetivo producir dos tipos de efectos: el primero, deshacer la jerarquía entre los tipos de discursos y las disciplinas, con el objetivo de evitar la reducción de lo real a un último nivel de explicación o a un sistema único de razones. Se trataría de producir una "homogeneidad transversal" de los tipos de saber, haciendo que, en un mismo espacio de verificación, valgan simultáneamente y en igual medida el concepto y la imagen, el relato original y el comentario filosófico, la literatura y la historia. Este efecto de la escena sobre las formas de conocimiento, sobre lo que cuenta como discurso, explica por qué Rancière describe, en un artículo publicado originalemnte en inglés bajo el título "Thinking between Disciplines: an Aesthetics of Knowledge" (2006), a su propia filosofía como una actividad "in-disciplinar" (p. 9).

El segundo efecto, que está íntimamente ligado con el primero, afectaría no el orden del discurso sino la naturaleza misma de los fenómenos a los que se refieren los diferentes tipos de saberes. La pérdida de una jerarquía causal absoluta en el nivel de la explicación discursiva va de la mano con una multiplicación de las formas de aparición de los fenómenos y de sus relaciones. Lo que vale, esta vez no como discurso sino como hecho, cambia al ser presentado por la escena. Los acontecimientos no se imponen o no se ordenan según un criterio fijo de significatividad, sino que aparecen según "lógicas" singulares, que dependen exclusivamente del corte que se produce al escoger la escena y distribuir sus elementos. Por eso, Rancière (2014) afirma que, siempre que sea posible localizar una alteración significativa del tejido sensible de la experiencia, "es posible analizar una situación pequeña o grande en términos de acontecimiento” (p. 94). 
Ese método de la escena, que es un método de redistribución de las formas sensibles y de sus criterios de inteligibilidad, está puesto prácticamente a prueba en la composición de uno de sus libros recientes sobre el mundo sensible del arte tal y como se habría configurado desde finales del siglo XVIII hasta nuestros días: Aisthesis. Escenas del régimen estético del arte (2013). En él, la escena vuelve a tener este valor explícito de operador metodológico y de composición:

Para estudiar estas mutaciones del tejido sensible por el cual hay arte para nosotros [...], decidí tomar unas cuantas escenas particulares. [...] Cada una de las escenas presenta, por lo tanto, un acontecimiento singular y explora, en torno de un texto emblemático, la red interpretativa que le da su significación. El acontecimiento puede ser una representación teatral, una conferencia, una exposición, la visita a un museo o un taller, la salida de un libro o el estreno de un filme. La red construida a su alrededor muestra de qué manera una actuación o un objeto se sienten y se piensan como arte, pero también como una proposición de arte y una fuente de emoción artística singulares, una novedad o una revolución en el arte e incluso como un recurso de este para salir de sí mismo. El arte los inscribe así en la constelación en movimiento donde se forman los modos de percepción, los afectos y las formas de interpretación que definen un paradigma artístico. La escena no es la ilustración de una idea. Es una pequeña máquina óptica que nos muestra al pensamiento ocupado en tejer los lazos que unen percepciones, afectos, nombres e ideas, y en constituir la comunidad sensible que esos lazos tejen y la comunidad intelectual que hace pensable el tejido. La escena aprehende los conceptos en acción, en su relación con los nuevos objetos de los que procuran apropiarse, los viejos objetos que intentan pensar de nuevo y los esquemas que construyen o transforman con ese fin (p. 11).

Están sin duda presentes los dos efectos de in-disciplinariedad y de multiplicidad de estrategias de significación que caracterizan el uso metodológico de la escena. Sin embargo, debemos notar acá la aparición de un vínculo suplementario, aquel que se da entre la unidad de verificación -la escena propiamente dicha- y aquello que ella debe mostrar - un régimen de identificación de las artes-. La noción rancieriana de "regímenes de las artes", que es introducida en El reparto de lo sensible (2000/2009a) y que sigue estando en uso en su obra actual, añade 
una complicación importante. La escena no se explica solamente por el corte singular que propone de un mundo sensible cualquiera, sino que ese mundo que la escena recorta, al menos si se trata del conjunto de prácticas que llamamos artísticas, está determinado históricamente por un sistema de evidencias sensibles y una red de modos de conceptualización que definen lo que cuenta como arte. Y si bien la presentación cronológica de esos "modos de pensabilidad" o regímenes del arte no es suficiente para afirmar que haya algo así como una "historia del arte" 17 en Rancière, la sucesión necesaria que va del régimen ético de las imágenes -en Platón- pasa por el régimen poético o representativo -presente desde Aristóteles hasta las Bellas Letras del siglo XVII- hasta llegar finalmente al régimen estético -forma de comprensión y de presentación del arte desde la época romántica hasta el arte contemporáneo- sí indexa las verificaciones de la escena a un principio de orden que no le es totalmente inmanente. Este mínimo de historia hace que los acontecimientos enmarcados en la escena no solamente hagan referencia a su propia temporalidad, sino que además estén presentando una sucesión de "separaciones" o de "oposiciones" entre diferentes regímenes de visibilidad del arte. Hay otra línea temporal, más amplia y más rígida, que proporciona el relato global de los cambios de lo que se entiende por arte -la secuencia de los regímenes ético, poético y estético-y define las formas generales internas de cada momento, los límites de cada régimen. Entre el tiempo externo de la sucesión de los regímenes del arte y la duración inmanente de los recortes de la escena se abre una distancia difícil de transitar.

Dos de los problemas ligados a esta distancia nos interesan particularmente: el primero, que podemos llamar problema de potencia o capacidad expresiva, consiste en determinar cómo es posible que la unidad inferior -la escena- muestre o exponga efectivamente la unidad superior a la que pertenece -el régimen-. El segundo, el problema del orden de presentación, consiste en conocer cómo la secuencia de las unidades inferiores se relaciona con la coherencia del régimen al que pertenecen.

17 Sobre la ausencia de una "historia del arte" en Rancière y su relación con los conceptos de régimen artístico y de estética, me permito referir a mi artículo "Esthétique et effectivité de la pensée : à propos du spectateur d'art chez Rancière" en Revue Proteus - Cabiers des théories de l'art (Alvarado, 2012). 
Una forma de disolver esta serie de problemas consiste en anular la diferencia describiendo toda experiencia consistente -lo que incluiría evidentemente la noción de régimen- en términos de la escena. Podemos llamar a este movimiento "hipérbole fenomenológica de la escena". Se trata de la tentación de pasar de la condición "cuasi-trascendental" que ofrece la escena -el hecho de que la escena, bajo ciertas condiciones, permite pensar las determinaciones espacio-temporales de la representación- a la asunción de su carácter plenamente trascendental. Nos parece que es precisamente lo que ocurre con la posición de Esa Kirkkopelto, dramaturgo y filósofo del teatro, cuando afirma en "The Question of the Scene: On the Philosophical Foundations of Theatrical Antropocentrism" (2009) lo siguiente:

El teatro abre una cierta manera de ver donde nuestra relación con el mundo puede aparecer libremente. La exclusión de la realidad, usualmente entendida como condición de la realización de una representación teatral, debe ser entendida, entonces, como condicional, relativa y temporal, como un medio para hacer visibles algunas de nuestras relaciones con el mundo que de otra manera no saldrían a la luz. Esta es la archi-opsis de la acción teatral, y estas son las condiciones para la realización de todas las soluciones escénicas individuales (p. 231) ${ }^{18}$.

Más adelante, el autor finlandés es aún más enfático: “[...] nuestra experiencia nace teatral, y la teatralidad da la forma de la modalidad a priori, la pre-comprensión, de nuestra experiencia; y es a través de y conforme con esta experiencia que nos encontramos con las cosas del mundo" (p. 232) ${ }^{19}$.

El texto invita a múltiples comentarios, pero nos limitamos a una sola objeción: ¿cómo se garantiza que, en el teatro, más que en cualquier otra actividad humana, se hagan transparentes las estructuras trascendentales de la experiencia?,

18 "The theatre opens up a certain optics where our relationship with the world can appear freely. The exclusion of reality, usually understood as the condition for the realization of a theatrical performance, is therefore to be understood as conditional, relative and temporary, as a means of making certain things in our world relationship apparent which might otherwise not come to view. This is the archiopsis of theatrical action, and it is on these conditions that all individual scenic solutions are realized".

19 "Our experience is born theatrical, and theatricality forms the a priori modality, the pre-understanding, of our experience, through and according to which we encounter the things of the world". 
¿por qué, en últimas, llamar teatral a esta precomprensión? Kirkkopelto, en línea con los elementos o las funciones de la escena que propusimos antes, nos dice que la puesta en escena pone en perspectiva, circunscribe y encuadra, la experiencia del mundo. Añade, además, que esa puesta en escena del mundo solo funciona, solo hace visibles los fenómenos, en la medida en que ella misma se sustrae a la mirada. Pero en todas estas descripciones, que elevan la escena al estatuto de lo trascendental y cuyo contexto de discusión es abiertamente filosófico, lo que se pierde es precisamente el conjunto de determinaciones históricas, técnicas y materiales que forman lo que nosotros entendemos hoy como arte teatral.

¿Cómo evitar este salto injustificado a lo trascendental, sin perder con ese gesto la posibilidad de pensar las operaciones filosóficas a la luz de las prácticas teatrales? ¿Cómo recuperar la especificidad de la analogía y aclarar los problemas que habíamos encontrado en su uso metodológico? Volviendo a atender a la realidad histórica de la práctica escénica, a la manera como se han configurado materialmente sus dispositivos de representación y como se ha organizado el saber reflexivo a partir de las contingencias de su cuerpo técnico. Lo que significa: respetar el devenir autónomo de los problemas teatrales y de sus soluciones prácticas.

\section{La escena y el orden del discurso dramático en el teatro francés del siglo XVII}

El eJEMPLO DE UN EXAMEN De ESTE TIPo, histórico y técnico, con el que cerraremos este artículo, está basado en otro uso de la palabra escena, que había sido ignorado hasta este momento en la discusión. Se trata de la escena, no como espacio de representación, sino como unidad del discurso dramático y como principio de organización de algunos de sus elementos. Este uso tardío del término data, en el área francófona, de finales del siglo XVI y comienzos del siglo XVII.

Partamos entonces de la noción clásica de escena como unidad o segmento de composición dramática tal y como aparece en la obra La pratique du théâtre del abad d'Aubignac (1657/2011), tratado que era una codificación tardía de la tendencia normativa y racionalista de la poética teatral de la segunda mitad del siglo XVII. Al contrario de lo que ocurría con los actos, que estaban determinados a priori, en su función y en su número, por límites genéricos transversales -cinco 
actos por pieza, trescientos versos cada acto-, la escena solo era especificable a través de procedimientos locales de distinción y de enumeración. Este principio está claramente presente en la definición que da d'Aubignac: "una escena es esa parte de un acto que aporta algún cambio al teatro a través del cambio de los actores" (p. 358) ${ }^{20}$. La regla del cambio sigue siendo extensiva, lo que quiere decir que la identidad de una escena no implica nada más que la presencia simultánea de un número determinado de personajes. En un primer momento, las relaciones particulares de los personajes entre ellos no intervienen en la formación o en la localización de una escena como unidad dramática. Solo importa el número, todo cambio de cardinalidad posee la potencia de dividir un acto en escenas.

Pero esa condición se vuelve difusa en el momento en el que se examinan los bordes o los límites de las escenas. Establecer correctamente el encadenamiento entre las escenas era, en el siglo XVII, una apuesta esencial para defender la disposición racional del discurso teatral. Lo que estaba en juego era precisamente la efectividad del esquema causal en el nivel más elemental de la segmentación dramática. Sin embargo, esta defensa de la causalidad choca con problemas insospechados, que proyectan una sombra barroca sobre este espacio clásico, al dividir el discurso dramático en dos niveles de articulación diferentes. En efecto, el problema consiste en que los principios que permiten dar cuenta del pasaje entre los elementos en el orden superior -los actos- se vuelven incapaces de dar cuenta de la organización y del pasaje entre los elementos del orden inferior -las escenas-, que sin embargo están incluidas como partes de las unidades de rango superior. La ley que asegura la coherencia orgánica de la fábula, desde el exterior y en relación con la unidad de la acción representada, se llama, en una tradición a la vez aristotélica y horaciana, "la verosimilitud y la necesidad". Es la verosimilitud la que encadena la serie de elementos dramáticos según el agenciamiento propio de los hechos representados -es decir, el orden lógico de la historia es el que ordena las unidades del relato de una manera necesaria-. Pero esta organicidad es muy difusa cuando se ve en el nivel de los componentes de la escena. En la focalización restringida de ese nivel inferior, las razones por las cuales un personaje determinado -o un conjunto de personajes-, y no otro, deba ser el que

20 «Une scène est cette partie d'un acte qui apporte quelque changement au théatre par le changement des acteurs. 》 
ponga en marcha la diferencia entre dos escenas no pueden ser más que anticipaciones parciales, puntos de tensión inmanentes que se resuelven caso por caso. Esta regulación de la estructura de las escenas y de sus bordes recibía un nombre muy preciso en el drama trágico clásico: el enlace entre escenas. El ajuste del cambio de los segmentos inferiores, entonces, no puede sostenerse por la obediencia de la escena a una ley externa, a un criterio de unidad de la representación. El enlace entre escenas es, al contrario, el lugar donde la causalidad dramática, la ley de la verosimilitud, para poder sobrevivir en el nivel del segmento superior, debe disolverse en una casuística poética. D’Aubignac (1657/2011) es consciente de este asunto al afirmar que: "escoger a la persona que va a hablar en estos encuentros, y el lugar donde debe hablar, todo esto depende absolutamente del juicio del poeta" (p. 376)

Ahora bien, como ese juicio es una escogencia inmanente, específicamente localizada en una situación, los enlaces no dejan de complejizarse, y se produce una superabundancia de especies. Se trata de una tarea que la mayoría de los poetas y de los teóricos clásicos emprendieron apasionadamente, una suerte de júbilo de invención frente a la impotencia local de la ley, pero en vista de su salvación general. Solo en el tratado de d'Aubignac se pueden encontrar cinco tipos distintos de enlaces: de presencia, de búsqueda, de ruido, de tiempo y de fuga. Todas estas formas de enlaces son formas de decisión o de juicio de casos particulares. Hacen intervenir el cambio entre los segmentos dramáticos inferiores, modificando algunos puntos singulares de los elementos que constituyen la escena. Una diferencia entre escenas se efectúa entonces, por ejemplo, en relación a la discontinuidad de la presencia de un elemento, es decir, de un personaje -enlace de presencia-; a través de reemplazos e intercambios de los elementos -enlace de búsqueda-; por la introducción de índices difusos, eventos menores que pasan, o que suenan, en los bordes de las zonas visibles de la escena -enlace de ruido-; o se puede producir el cambio por el puro azar que hace que un término venga a remplazar a otro en el momento propicio -enlace de tiempo- o que se retire del escenario sin razón evidente -enlace de fuga-.

21 «Pour choisir la personne qui va parler en ces rencontres, et l'endroit où elle doit parler, cela dépend absolument du jugement du poète. » 
Es evidente que se pueden producir muchas más series de enlaces. Pero también lo es que, en todas, el criterio de orden no está exclusivamente dado por la extensión. Los pasajes entre las escenas, independiente del tipo de enlace, se deciden en función de rasgos intensivos de algunos de sus elementos, por relaciones de vecindad o de distancia. Si se quiere pensar entonces el cambio de las escenas, hay que apoyarse, más allá del contenido numérico, en la forma tensa y específica de sus materiales. De hecho, Jacques Scherer demostró ya, en su estudio $L a$ dramaturgie classique en France (1986), que la realidad material de la escena era indispensable para pensar el fenómeno del enlace:

Si el problema del enlace de las escenas preocupó a los teóricos y a los autores dramáticos durante unos treinta años, de 1630 a 1660 aproximadamente, fue menos por razones exclusivamente de estética literaria provenientes de la doctrina clásica que porque cada entrada y cada salida de un actor es, en el siglo XVII, una operación lenta y delicada. Nos esforzaremos por mostrar, interpretando los pocos documentos precisos de los que disponemos, que, en la mayoría de los casos, el escenario [plateau] es relativamente profundo, que el actor entra siempre por el fondo, que le cuesta trabajo introducirse hasta el escenario y avanzar, que camina lentamente, y que está obligado a llegar hasta la parte de adelante, para actuar lo más cerca posible de los espectadores (p. 266) $)^{22}$.

¿Qué nos deja como tarea filosófica esta última noción de escena, extraída de las vicisitudes técnicas del teatro? Quisiera nombrar a ese problema, provisionalmente, como el problema de la variación de escala del discurso. Al crear o al pensar un discurso, la focalización sobre ciertos tipos de elementos puede implicar una variación del sistema de orden al que están sometidos. No se trata de la postulación de un conjunto jerárquico de niveles ontológicos independientes,

22 «i le problème de la liaison des scènes a préoccupé les théoriciens et les auteurs dramatiques pendant une trentaine d'années, de 1630 à 1660 environ, c'est moins pour des raisons d'esthétique littéraire relevant de la doctrine classique que parce que chaque entrée ou sortie d'un acteur est, au XVIIe siècle, une opération lente et délicate. Nous allons en effet nous efforcer de montrer, en interprétant les rares documents précis dont nous disposons, que dans la plupart des cas, le plateau est relativement très profond, que l'acteur entre par le fond, qu'il a du mal à pénétrer sur le plateau et à avancer, qu'il marche lentement, et qu'il est obligé de venir jusque sur le devant, pour jouer le plus près possible des spectateurs. 》 
de tal forma que, por ejemplo, los niveles superiores puedan ser reducidos en términos de los inferiores. Se trata, de hecho, de evitar esta multiplicación de niveles ontológicos, al mismo tiempo que se permite un efecto real de variación por el ajuste de escala o de enfoque.

Lo interesante del ejemplo de la escena es que el paso del nivel del acto al nivel de la escena no es un proceso de reducción, no solo porque los elementos de la escena -por lo menos los que permiten pensar el enlace- son considerablemente más complejos o más ricos en determinaciones que los elementos de la cadena causal de los actos, sino además porque desde el puro nivel de la escena es imposible dar cuenta de la forma de orden del nivel superior. No hay, en el teatro clásico, un agregado azaroso de cortes escénicos que valgan por sí mismos ${ }^{23}$ y que luego, por un efecto indeterminado o indecidible, se organicen espontáneamente en una fábula orgánica.

Podría entonces esperarse que, aunque el paso del acto a la escena no sea una simplificación, el paso de la escena al acto sí pueda ser descrito como un proceso de abstracción, como si en el nivel superior de los actos, y para efectos de la construcción del relato dramático, se conservasen de la escena solo los elementos relevantes para garantizar la verosimilitud de los hechos representados y la necesidad de su secuencia. Ahora bien, tampoco parece ser el caso, ya que ninguno de los elementos de la escena es propiamente filtrado o seleccionado en detrimento de otros; todos los elementos de la escena son también elementos del acto. Es más, siendo la unidad de la escena el lugar por excelencia de lo aleatorio y lo contingente, la defensa de los cambios de fortuna y de la interrupción de las acciones de los héroes por "potencias superiores" de autores clásicos como Corneille por ejemplo en "Trois discours sur le poème dramatique" (1987)- puede leerse como una apuesta por la importancia específica de ese nivel de composición.

Esta lógica propia de la composición dramática, donde las diferencias de escala o los saltos de nivel producen variaciones de sentido en el discurso y en su organización, pero que, al mismo tiempo, mantiene inseparables e implicados sus diferentes estratos de descripción, puede servir para intentar dar curso a las cuestiones que surgieron al examinar el uso de la escena en la filosofía de Jacques

23 Este sería, sin embargo, el caso de las escenas del teatro épico, según la descripción de Brecht (2004) en "Sobre una dramática no aristotélica" en Escritos sobre el teatro. 
Rancière: el problema de la potencia expresiva de la escena y el del orden de la presentación. Si la escena rancieriana es capaz de exponer el régimen del arte en el que se inscribe no es porque se presente como una versión en miniatura del mismo espacio y de las leyes que lo componen, un "microcosmos" como lo llama el mismo autor, sino porque expone a la lógica del régimen a medirse a determinaciones materiales inéditas. Tal y como ocurre con los enlaces del teatro clásico, los cambios entre las escenas del filósofo extienden y transforman la ley que define un régimen, forzando su contacto con la contingencia y la singularidad técnica de los mundos sensibles que describe. Las verificaciones que producen esas "pequeñas máquinas ópticas" no son la representación de la identidad de la ley del régimen sino sus puntos de pasaje y transformación creativa. De la misma manera, la forma en que la escena influye en la composición de la secuencia del nivel superior no está dada por la repetición, en el nivel inferior, de las mismas reglas de orden que constituyen la lógica del régimen artístico. Hay que recordar que, salvo por la manera en que trata sus bordes, una escena dramática no presenta ninguna diferencia fundamental con el acto. Pero es precisamente por articular las unidades del discurso a sus puntos de tensión, por enlazarlos según un sistema de reglas inmanentes y que varían de caso en caso, que la temporalidad de la escena interviene en la temporalidad general del régimen. Suplementa el tiempo homogéneo, el tiempo de la invariancia de las condiciones que definen a un régimen artístico como un todo determinado, punteándolo con casos polémicos, multiplicando los esquemas posibles de aplicación. La escena divide o dialectiza el tiempo del régimen, lo trabaja desde su interior al abrirle zonas nuevas de operación. Esto explica por qué, en los libros en los que Rancière organiza históricamente sus descripciones de un régimen artístico - particularmente en La palabra muda (2009b) y en Aisthesis (2013)- la impresión que queda no es la de un orden cronológico único, la de una progresión lineal, sino la de un orden complejo, atravesado por una serie de secuencias distintas. Así como el proyecto estético de un artista o de un escritor puede ser la radicalización o la oposición de una tentativa inmediatamente anterior, también ocurre que, entre las escenas, se trazan continuamente otro tipo de trayectos: préstamos y herencias discontinuas entre artistas que no siempre trabajan en el mismo medio; esquemas estéticos diferentes para los mismos problemas sensibles; relatos de la crítica que saltan de un espacio al otro, que se pierden durante un tiempo para después resurgir bajo una forma inesperada. 
Si el efecto de cambio de escala esclarece, aunque sea parcialmente, los problemas del uso metodológico de la escena -la tensión entre la lógica singular que une a las escenas de Rancière y la consistencia de la categoría más general de régimen estético- nos parece una razón suficiente para preferir este tipo de acercamiento a aquellos que parten exclusivamente de las categorías filosóficas para después forzar su comparación con las prácticas artísticas. Sin duda, estos resultados tendrían que analizarse con mayor detenimiento y es necesario verificar su utilidad o su pertinencia en otros contextos. Pero aun con este carácter incompleto, el examen que realizamos nos parece ofrecer una última consecuencia, una suerte de imperativo ético para la investigación del vínculo entre el teatro y la filosofía: nos muestra cómo el interés y la productividad de la relación entre los dos campos aumenta en la medida en que los filósofos nos acercamos a los fenómenos artísticos respetando la integridad de su devenir histórico y la complejidad de sus propias estrategias formales.

\section{Referencias}

Alvarado, N. (2012). Esthétique et effectivité de la pensée : à propos du spectateur d'art chez Rancière. Revue Proteus - Cahiers des théories de l'art, 4, 49-57.

Aristóteles. (1999). Poética. Madrid: Gredos.

Badiou, A. (2004). El siglo. Buenos Aires: Manantial.

Badiou, A. (2005). Teatro y filosofía. Imágenes y palabras. Escritos sobre cine y teatro (pp. 115-135). Buenos Aires: Manantial.

Badiou, A. (2010). Segundo manifiesto por la filosofía. Buenos Aires: Manantial. Badiou, A. (2015a). Éloge du théâtre. Paris: Flammarion.

Badiou, A. (2015b). Rapsodia por el teatro. Buenos Aires: Adriana Hidalgo Editora.

Bardet, M. (2011). Penser et mouvoir. Une rencontre entre danse et philosophie. Paris: L'Harmattan.

Brecht, B. (2004). Escritos sobre el teatro. Barcelona: Alba.

Claudel, P. (1956). Conversation sur Jean Racine. Paris: Gallimard.

Corneille, P. (1987). Trois discours sur le poème dramatique. OEuvres complètes (Tome III). Paris: Gallimard.

D’Aubignac. (2011). La pratique du théâtre. Paris: Honoré Champion. 
Deleuze, G. (2002). Diferencia y repetición. Buenos Aires: Amorrortu.

Derrida, J. (1992). La escritura y la diferencia. Barcelona: Anthropos.

Derrida, J. (2015). La diseminación. Madrid: Fundamentos.

Diderot, D. (1876). CEuvres complètes. Tome onzième. Salon de 1767. Paris: Garnier Frères, Libraires-éditeurs.

Diderot, D. (1981). Paradoxe sur le comédien. Précédé des Entretiens sur le Fils naturel. Paris: Flammarion.

Didi-Huberman, G. (2007). La invención de la histeria. Charcot y la iconografía fotográfica de la Salpêtrière. Madrid: Ediciones Cátedra.

Foucault, M. (1994a). Theatrum philosophicum. Dits et écrits (Tome II). Paris: Gallimard.

Foucault, M. (1994b). La scène de la philosophie. Dits et écrits (Tome III). Paris: Gallimard.

Freud, S. (1992). De la historia de una neurosis infantil. Obras completas. De la histoira de una neurosis infantil (el "Hombre de los lobos") y otras obras (19171919). Buenos Aires: Amorrortu.

Hallward, P. (2006). Jacques Rancière et la théâtrocratie. En: L. Cornu \& P. Vermeren (Eds.). La philosophie deplacée. Autour de Jacques Rancière (pp. 483489). Bourg en Bresse: Horlieu Éditions.

Kirkkopelto, E. (2009). The Question of the Scene: On the Philosophical Foundations of Theatrical Antropocentrism. Theater Research International, 34(3), 230-242. doi:10.1017/S0307883309990034

Lacan, J. (2014). Seminario 6. El deseo y su interpretación. Buenos Aires: Paidós. Lacoue-Labarthe, P. (2002). La poétique de l'histoire. Paris: Éditions Galilée.

Lacoue-Labarthe, P., \& Nancy, J-L. (2013). Scène. Paris: Christian Bourgois.

Proust, F. (1994). L'Histoire à contretemps. Paris: Les Éditions du Cerf.

Proust, F. (1997). De la résistence. Paris: Les Éditions du Cerf.

Quinet, A. (2010). L'inconscient structuré comme un théâtre. Savoir et clinique, I(12), 188-195.

Rancière, J. (2006). Thinking between Disciplines: an Aesthetics of Knowledge. Parrhesia, 1, 1-12.

Rancière, J. (2007). El teatro de las imágenes. En: A. Valdés. (Ed.). La politica de las imágenes (pp. 69-91). Santiago de Chile: Metales Pesados. 
Rancière, J. (2009a). El reparto de lo sensible. Estética y política. Santiago de Chile: ARCES-LOM.

Rancière, J. (2009b). La palabra muda. Ensayo sobre las contradicciones de la literatura. Buenos Aires: Eterna Cadencia.

Rancière, J. (2010). El desacuerdo. Buenos Aires: Nueva Visión.

Rancière, J. (2013). Aisthesis. Escenas del régimen estético del arte. Buenos Aires: Manantial.

Rancière, J. (2014). El método de la igualdad. Conversaciones con Laurent Jeanpierre y Dork Zabunyan. Buenos Aires: Ediciones Nueva Visión.

Rancière, J. (2015). El hilo perdido. Ensayos sobre la ficción moderna. Buenos Aires: Manantial.

Rousseau, J.-J. (1995). Lettre à D’Alambert. CEuvres complètes. Tome V. Écrits sur la musique, le langage et le théatre. Paris: Gallimard.

Scherer, J. (1986). La dramaturgie classique en France. Paris: Nizet.

Szondi, P. (2011). Teoría del drama moderno (1880-1950). Tentativa sobre lo trágico. Madrid: S. L.-Dykinson.

Wardhaugh, J. (2017). Popular Theater and Political Utopia in France 18701914. Active Citizens. Londres: Palgrave Macmillan. 